\title{
Morphometrical and histochemical studies of cardiac muscle
}

\author{
A comparative ultrastructural study with special \\ reference to rat and guinea pig \\ Ryoichi Nakagawa, Kohoji Kameyama, Goro Asano, Jose, M. Gonzalez*, \\ Yasuhisa Hirohata*, Tatsuo Oguro*, and Hiroshi Kobayashi* \\ The Second Department of Pathology, Central Institute for Electron Microscopic Researches*, \\ Nippon Medical School
}

\begin{abstract}
Summary
The authors have investigated the morphological and enzyme cytochemical differences at the level of electron microscopy in atrial and ventricular myocardium of rat and guinea pig. The ultrastructural and morphometrical observations have revealed that atrial cells tend to have very few $T$ tubules and that Golgi complex and specific dense granules were well developed in atria compared to ventricles. Histochemically, the reaction product of $\mathrm{Na}-\mathrm{K}$ ATPase was localized on the plasma membrane and T-tubules in rats similar to that of guinea pigs. The $\mathrm{DAB}$ positive bodies were localized in proximity to mitochondria and sarcoplasmic reticulum and measured from $0.1 \mu$ to $0.5 \mu$ in diameter in both animal species and were noted both at $\mathrm{pH} 5.0$ and $\mathrm{pH} 9.0$ in rat myocardial cell. However, in the guinea pig the reaction was observed only at $\mathrm{pH} 9.0$ or very faintly at $\mathrm{pH}$ 5.0. The DAB positive bodies were localized in subsarcolemmal region, close to the sarcoplasmic reticulum in atria. The activity of acid phosphatase in atria was higher than ventricles since the Golgi complex and subsarcolemmal citern were more highly developed in atria, but the specific granules in atria were devoid of the acid phosphatase activity. Alkaline phosphatase was confined to the endothelium of blood vessels and on the plasma membrane of heart cells. The glucose-6phosphatase was distributed in the sarcoplasmic reticulum, the nuclear membrane and the Golgi complex.
\end{abstract}

Key words : cardiac muscle, ultrastructural morphometry, Na-K ATPase, peroxisome, specific phosphatase

\section{Introduction}

It is evident that the myocardial cell of atrium, ventricle, and the Purkinje fibers have a different function and show a different response by various kinds of drugs, digitalis, vanadate, and others ${ }^{1 \sim 3)}$.

Physiological differences between atrial and ventricular cardiac cell suggest that there may also be associated with differences in the fine structural component of their cells. The 
activity of cardiac cells is determined by their inherent automaticity, local environments, and the presence of neurohumoral substances. The pharmacological agents can alter cardiovascular function by interfering with the effector cells or by altering the production of neurohumoral substances ${ }^{4}$.

For example, vanadate has shown a positive inotropic effect on ventricular tissue, but a negative inotropic effect on the atria of guinea pigs when compared to other animals ${ }^{2}$. This may suggest that a morphological and functional difference of the cell exists in the heart cells of atria and ventricles in various species. However, the differences between atrial and ventricular muscle cells have been less extensively studied. Therefore, the ultrastructural and enzyme histochemical study of the heart will prove to be a valuable reference in the correlation of the morphological, physiological and pharmacological properties of the cardiac muscle cell.

\section{Materials and Methods}

(1) Transmission electron microscopic observation

The heart tissues were taken from adult guinea pigs and rats. The hearts were perfused via aorta with $4 \%$ paraformaldehyde in $0.17 \mathrm{M}$ cacodylate buffer, $\mathrm{pH} 7.4$ for 5 minutes. Small pieces of atria and ventricles of the heart were fixed for an additional two or three hours at $4^{\circ} \mathrm{C}$, in $4 \%$ paraformaldehyde and $2.5 \%$ glutaraldehyde solution respectively, washed by $0.16 \mathrm{M}$ cacodylate buffer, $\mathrm{pH} 7.4$ and postosmificated with $1 \%$ osmium tetraoxide in 0.17 cacodylated buffer, $\mathrm{pH} 7.4$ for 30 minutes, dehydrated by graded alcohol and propylene oxide and embedded in Spurr. Thin sections from representative and longitudinal oriented blocks were cut by LKB ultramicrotome and examined with the Hitachi $12 \mathrm{~A}$ electron microscope. The electron microscope picture were analyzed by the Leitz ASM image analysis system.

(2) Ultrastractural histochemical observation

The excised heart was perfused via the aorta with a mixture of $2 \%$ paraformaldehyde and $0.2 \%$ glutaraldehyde in $0.17 \mathrm{M}$ cacodylate buffer (295 m OSM), $\mathrm{pH} 7.4$, for 5 minutes.

Several pieces of the left atria and ventricles were fixed for additional 10 to 15 minutes at $4^{\circ} \mathrm{C}$ in the fresh fixative.

Sections (40 60 $\mu$ thick) were cut from each block with a vibratome (Oxford) and the sections were incubated for 30 minutes to one hour at room temperature in standard incubation medium as followed.

1) $\mathrm{Na}-\mathrm{K}-\mathrm{ATPase} \mathrm{T}^{5}$

Asano medium which contained $1 \mathrm{~m} l$ of $20 \mathrm{mM}$ disodium p-nitrophenyl phosphate, $1 \mathrm{~m} l$ of $20 \mathrm{mM} \mathrm{MgCl}_{2}, 1 \mathrm{ml}$ of $20 \mathrm{mM} \mathrm{SrCl}$, and $1 \mathrm{~m} l$ of $20 \mathrm{mM} \mathrm{KCl}$ and $1 \mathrm{~m} l$ of $0.2 \mathrm{M}$ tris$\mathrm{HCl}$ buffer, $\mathrm{pH} 7.4$ and treated with $2 \%$ lead nitrate.

2) Catalase ${ }^{6)}$

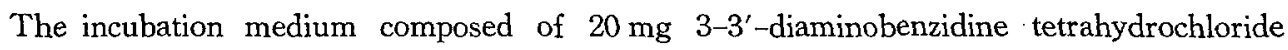
(DAB, Sigma Chemical Co.) $9.8 \mathrm{ml}$ of $0.05 \mathrm{M}$ tris buffer $\mathrm{pH} 9.5$ and $0.2 \mathrm{~m} l$ of $1 \%$ freshly diluted hydrogen peroxide was used at $\mathrm{pH} 5.0$ and $\mathrm{pH} 9.0$, respectively. 
3) Alkaline phosphatase ${ }^{6}$

The Ogawa-Mayahara medium which is composed of $1.4 \mathrm{ml}$ of $0.1 \mathrm{M}$ tris buffer, $\mathrm{pH}$ $8.5,20 \mathrm{~m} l$ of $0.1 \mathrm{M}$ sodium $\beta$-glycerophosphate, $2.6 \mathrm{ml}$ of $0.015 \mathrm{M}$ magnesium sulfate and $4.0 \mathrm{ml}$ of $0.5 \%$ lead citrate, $\mathrm{pH} 10$ was used.

4) Acid phosphatase ${ }^{\text {7) }}$

The Gomori-Novikoff medium contains $45 \mathrm{mg}$ cytidine-5'-monophosphate, $11 \mathrm{ml}$ of 0.1 $\mathrm{M}$ acetate buffer, $\mathrm{pH} 5.0,15 \mathrm{ml}$ of distilled water and $3.0 \mathrm{ml}$ of $1 \%$ lead nitrate was used.

5) Glucose-6-Phosphatase

The incubation medium is composed of $20 \mathrm{~m} l$ of $0.2 \mathrm{M}$ tris-maleic buffer, $\mathrm{pH} 6.7,27$ $\mathrm{m} l$ of distilled water, $25 \mathrm{mg}$ of glucose-6-phosphate, $3 \mathrm{~m} l$ of $2 \%$ lead nitrate and $4 \mathrm{~g}$ of sucrose.

In addition to the above, in order to evaluate the specificity of enzyme, the following controls were prepared from the same animals, (1) Deletion of substrate, (2) Addition of $10 \mathrm{mM}$ ouabain as an inhibitor for Na-K-ATPase, (3) An additional $10 \mathrm{mM}$ of sodium fluoride was used as an inhibitor for acid phosphatase and $0.1 \mathrm{M}$ bromotetramisole as an inhibitor for alkaline phosphatase was used. The sections were rinsed twice for an interval of 10 minutes and were post-fixed for an hour in $2 \%$ osmium tetroxide at $4^{\circ} \mathrm{C}$, rinsed, dehydrated through graded ethanols and propylene oxide and embedded in Spurr. The sections were examined, either unstanined or stained, with uranyl acetate and lead citrate.

\section{Results}

\section{Ultrastructural and Morphometrical observation}

The atrial cells tend to be smaller than ventricular cells. In the atria, the sarcoplasm has more prominent Golgi complex, vesicles, and dense granules than are present in the ventricle.

The mitochondria is pleomorphic in shape and measure in diameter of $0: 1 \mu$ or less. They distribute throughout the cytoplasm, but are particularly abundant in the cornial regions of cytoplasma at the end of nucleus. The volume of mitochondria in the atria is morphometrically less than in the ventricles (Fig. 1).

The principle difference between atrial and ventricular myocardium of the heart is in the degree of development of the T-system. The transverse tubular system are not present in conducting fibers as the cell of the SA or AV node, and in most atrial cells. The T-tubules are $1,500 \sim 2,000 \AA$ in diameter and their limiting membrane has a fibrillar coating on the luminal surface (Fig. 2). The T-system of the guinea pig has developed to be more distinguished than the rat in left ventricle (Fig. 1).

The numerous cytoplasmic dense granules, many of which are closely associated with the Golgi complex are present in atrial cells (Fig. 3). These granules with a dense content appear to arise in the Golgi complex and measure in diameter of $0.3 \sim 0.4 \mu$. These specific granules are found only in atria. The other pleomorphic dense bodies are found in atrial and ventricular cell of rat and guinea pig are similar to those in other tissue cells.

The coated dense vesicles are clearly associated with the sarcoplasmic reticulum, showing 

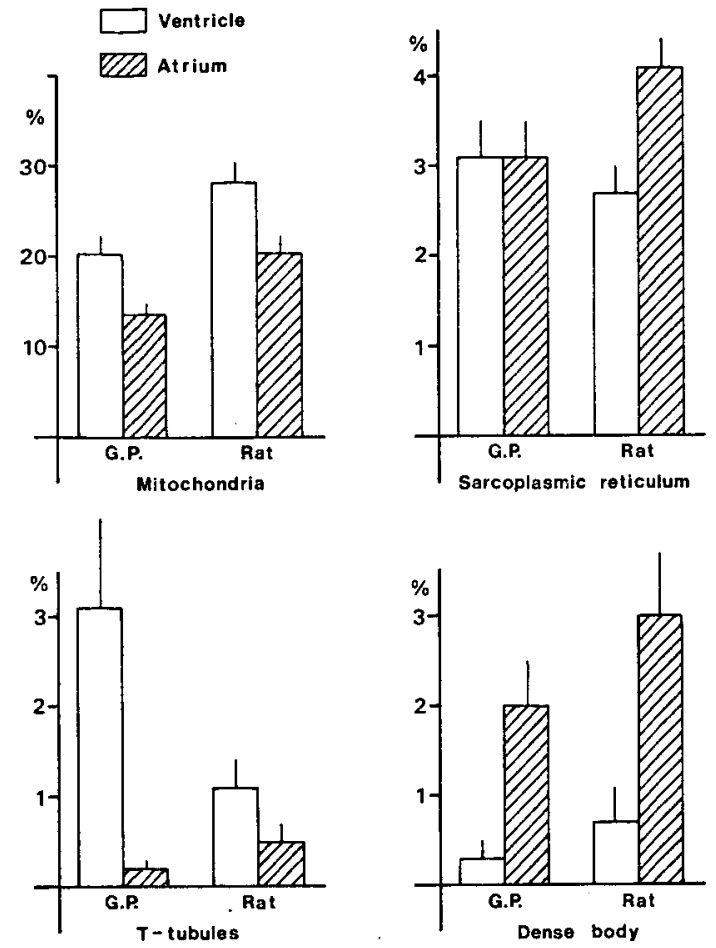

Fig. 1 Ultrastructural morphometric analysis on normal rat and guinea pig hearts (mean values \pm SE) catalase activity. In normal heart, lysosomes are consisted of spherical or ovoid bodies and are limited in distribution to the perinuclear zone. The sarcoplasmic reticulum of cardiac muscles show tubular structure and extend into cytoplasm that subdivide myofilaments into irregular myofibrils (Fig. 4). The sarcoplasmic reticulum is composed of smooth surface membranes and is a form of the agranular endoplasmic reticulum. There are numerous subsarcolemmal cisterns which lie in closely proximity to the internal surface of the sarcolemma in atrium (Fig. 5). The sarcoplasmic reticulum development in the atrium and the ventricle is identical in any species (Fig. 1). Generally, ribosomes may also exist free in the sarcoplasmic matrix, but are difficult to distinguish from the glycogen particles. There is considerable variation from one cell to another in the number of cellular components and arran. gement of the myofibrils in atria compared to ventricles.

\section{Histochemical observation}

According to the analysis of localization of Na-K ATPase in the myocardium by the modified Ernst method, the reaction product of $\mathrm{Na}-\mathrm{K}$ ATPase is localized on the plasma membrane and T-tubules (Fig. 6). The localization of $\mathrm{Na}-\mathrm{K}$ ATPase in rat is essentially similar to that of guinea pigs. The reaction product is diminished by oubain, and potassium deletion in the atria and ventricles. The amount of precipitation in mitochondria, sarcoplasmic reticulum and subsarcolemmal cisterns is unaffected by oubain or potassium deletion. According to this method, Na-K-ATPase is localized particularly in the intracellular side of the plasma membrane.

The enzymatic activity and distribution of $\mathrm{DAB}$ positive bodies in rat and guinea pig hearts are localized in proximity to mitochondria and sarcoplasmic reticulum and measure from $0.1 \mu$ to $0.5 \mu$ in both animal species (Fig. 7). Particularly, DAB positive bodies are localized in the subsarcolemmal region, with a close proximity to sarcoplasmic reticulum in atria (Fig. 8). DAB positive bodies are seen both at $\mathrm{pH} 9.0$ and $\mathrm{pH} 5.0$ in rat myocardial cells (Table 1). However, in guinea pigs, the reaction is observed only at $\mathrm{pH} 9.0$ or very faintly at $\mathrm{pH}$ 5.0.

The distribution of acid phosphatase activity is corresponded to the distribution of elements 
Table 1 Enzyme activity in the myocardial cell of rodent animals

\begin{tabular}{|c|c|c|c|c|c|}
\hline \multirow{2}{*}{ Cell organelle } & \multirow{2}{*}{ Enzyme } & \multicolumn{2}{|c|}{ Rat } & \multicolumn{2}{|c|}{ Guinea Pig } \\
\hline & & Atrium & Ventricle & Atrium & Ventricle \\
\hline \multirow[t]{2}{*}{ Plasma membranc } & $\mathrm{Na}-\mathrm{K}$ ATPase & + & + & + & + \\
\hline & Alkal ine phosphatase & + & + & + & + \\
\hline \multirow{4}{*}{$\begin{array}{l}\text { Sa coplasmic } \\
\text { ret iculum }\end{array}$} & Acid phosphatase & ++ & + & ++ & + \\
\hline & Alkaline phosphatase & - & - & - & - \\
\hline & Catalase, pH 5.0 & - & - & - & - \\
\hline & Na-K ATPase & - & - & - & - \\
\hline \multirow[t]{2}{*}{ Ly sosomes } & Acid phosphatase & ++ & ++ & ++ & ++ \\
\hline & Alkaline phosphatase & \pm & \pm & \pm & \pm \\
\hline \multirow{2}{*}{$\begin{array}{l}\text { Cytoplasmic } \\
\text { granules }\end{array}$} & Acid phosphatase & - & & - & \\
\hline & Catalase pH 5.0 & - & & - & \\
\hline \multirow[t]{2}{*}{ Peroxisomes } & Catalase. pH 9.0 & ++ & ++ & ++ & ++ \\
\hline & DH 5.0 & + & + & $\mathbf{t}$ & \pm \\
\hline \multirow[t]{2}{*}{ Mitochondria } & Catalase & \pm & \pm & \pm & \pm \\
\hline & Acid phosphatase & - & - & - & - \\
\hline \multirow[t]{2}{*}{ Golgi complex } & Acid phosphatase & ++ & \pm & ++ & \pm \\
\hline & Catalase & - & - & - & - \\
\hline
\end{tabular}

Enzyme activity marked: ++ , moderate: + , mild: \pm , negative: -

of the sarcoplasmic reticulum (Fig. 9) and Golgi complex. Additional reaction product is also noted in residual bodies and spherical lysosomes. The activity of acid phosphatase in atria is higher than in ventricles, since the Golgi complex and subsarcolemmal cisterns are more highly developed in atria. However, the specific dense granules in atria show no acid phosphatase activity and catalase activity. Lipid droplets are covered by a ring of granular dense reaction product enzymes such as acid and alkaline phosphatase, and lipofuscin granules are limited by acid phosphatase or DAB reaction. Alkaline phosphatase is confined to the endothelium of blood vessels and on the plasma membrane of heart cells and interstitial cells (Fig. 10). G-6-Pase activity is uniformly distributed in the sarcoplasmic reticulum, the nuclear membranes and the Golgi complex (Fig. 11).

\section{Discussion}

The morphological features are quite different between the atria and the ventricles in the rat and guinea pig. The distribution of the $T$-system are much less in atria than in ventricles. The scanty $T$-system in the atrial cell might be expected to speed conduction of the atrial potential because there would be less membrane to depolarize ${ }^{\text {9) }}$ Ashraf had reported that the surface to volume ratio of the T-system was slightly increased in the chronically stable hypertrophic hearts but was decreased substantially in the failing hearts, which reflects a great increase in the diameter of the T-tubules ${ }^{10)}$. These morphometric observations also suggest that the membrane system of sarcolemma and $\mathrm{T}$-system in myocardium is very important not only as a barrier system for the permeation of various substances but as conduction properties.

The sarcoplasmic reticulum is developed in various forms. The junctional sarcoplasmic reticulum is localized in adhere to transverse tubules and the surface sarcolemma. Functionally, the sarcoplasmic reticulum shows calcium binding activity in the heart cell and its abnormality in intracellular calcium metabolism may be a significant factor in the depression of contrac- 
tility $^{11,12)}$. The increase in sarcoplasmic reticulum volume and surface might be necessary to compensate for the decreased contractility of the failing stage of the heart ${ }^{10}$.

The mitochondria of cardiac muscle is more numerous in the ventricles than atria in rat and guinea pig. They are more pleomorphic than those of skeletal muscle ${ }^{13)}$. Generally the mitochondrial functions are associated with intracellular metabolism, and it was reported that the mitochondria was increased in number during a early stage of hypertrophy ${ }^{14}$.

Large populations of spherical, specific, granules, 0.3 to $0.4 \mu$ in diameter are characteristically found in mammalian atrial cells. Atrial granules are larger and more numerous in smaller species and generally smaller and less numerous in larger animals such as dog and human ${ }^{15)}$. Nucleoside diphosphatase and thyamine pyrophosphatase activity have been revealed in Golgi complex in the atrium than in ventricular muscle cells, possibly reflecting a role in the synthesis of atrial granules ${ }^{16}$. Ferrans ${ }^{17}$ suggested that the secretory function of atrial cell subject to control by neurohumoral agents and that it may be in some way related to cholinergic effects. The cholinergic receptors of the myocardial and vascular smooth muscle cells are muscarinic in nature. Acetylcholine inhibits the activity of the sinus and atrioventricular nodes, and depresses the other atrial cells, thus slowing heart. However, it has little effect on the ventricular myocardium ${ }^{4}$.

The localization of the ouabain-sensitive potassium dependent Na-K-ATPase might represent "receptor sites" for cardiac glycosides ${ }^{18}$. However, enzymatic activities at the junctional sarcoplasmic reticulum, subsarcolemmal cisterns and mitochondrial membranes were not sensitive to ouabain or to deletion of potassium ${ }^{5}$.

The cytochemical localization of Na-K-ATPase in the myocardial cell membrane adds further to the role of this enzyme in the regulation of cell volume ${ }^{19}$. The heart cell volume is maintained, by the $\mathrm{Na}-\mathrm{K}$ pump where hydrolysis of ATP provides the energy for the movement of potassium and sodium ions ${ }^{18}$. The application of this technique for identifying the distribution sites of $\mathrm{Na}-\mathrm{K}$-ATPase will be extremely useful for studying the cell injury and explaining physiological and biochemical differences between atrium and ventricle of the myocardium. Histochemically, we have shown that vanadate affects differently the activity of Na-K-ATPase in the atrium and ventricle of guinea pig heart ${ }^{20)}$. Vanadate is a specific $\mathrm{Na}-\mathrm{K}$-ATPase inhibitor with unlike cardiac glycosides which inhibit the sodium pump by binding to its extracellular side, and vanadate inhibits from the cytoplasmic side. Vanadate would be sensitive to the changes in cytoplasmic magnesium and ATP concentrations and extracellular potassium concentration ${ }^{21}$. The inhibition of the $\mathrm{Na}-\mathrm{K}$ pump increases the intracellular sodium concentration, followed by an increase in the intracellular calcium concentration. The increase in cytoplasmic calcium ion explains the positive inotropic effects of cardiac glycosides on the myocardium as well as their stimulation effect on the vascular muscle cells of the arterioles and the veins ${ }^{22}$.

These facts are extremely important from the electrophysiological view and they are well correlated with the morphological data we have obtained through this investigation. The myocardial cells usually contain electron dense bodies which were comprised of either peroxisomes or lysosomes ${ }^{6}$. Frequently, it become defficult to differentiate morphologically 
the peroxisomes from dilated sarcoplasmic reticulum vesicles or coated vesicles, since the vesicles may arise from dilatations of sarcoplasmic reticulum. However, the peroxisomes show DAB positive reactions. These bodies are oxidized by diaminobenzidine at acid and alkaline $\mathrm{pH}$ and are roughly round and spherical. Those are located near mitochondria and sarcoplasmic reticulum and are commonly discerned at Z-lines in the myocardium. The size and distribution of peroxisomes are different in various tissues and animal species ${ }^{23,24)}$. The function of the peroxisomes is assumed to be related with the lipid metabolism as they are closely associated with the sarcoplasmic reticulum ${ }^{23}$.

Acid phosphatase and alkaline phosphatase activities were not demonstrated in the peroxisomes. However the lipid droplets in the perinuclear zone showed catalase activity at $\mathrm{pH} 9.0$ and lipofuscin granules were limited by acid phosphatase and DAB reactions. The degeneration of myocardial cells following ischemic injury is associated with the releases of endogenous lysosomal enzymes from the sarcoplasmic reticulum ${ }^{25)}$. Important metabolic processes may be mediated by hydrolytic enzyme. Alkaline phosphatase activity was remarkable in capillary wall and endothelium and was faintly visible in muscle cells. At the earlier stage of development, phosphatase activity in ventricle is more present than in the atrium which is distributed along the endocardium of the left ventricle, and the total amount of alkaline phosphatase activity in young animals was less intense than the activities in the atria of mature rats $^{26)}$. The distribution of the coronary arteries in the heart of the guinea pig is basically similar to that of the rat with some variation in the length and extent of distribution of each coronary artery ${ }^{27}$. The localization of alkaline phosphatase of the plasma membrane of blood vessel and heart cells may be related to calcium transport and its function in this present study could not be ascertained ${ }^{28}$. Finnaly the distribution of glucose-6-phosphatase may suggest that the sarcoplasmic reticulum is an intracellular transport system concerned with the transport of glucose from glycogen containing sites ${ }^{28}$. We concluded that physiological and pharmacological specificity in the heart of various animals might be dependent of the structural and enzymatical properties of heart cells.

This work was supported by the Adult Disease Clinic Memorial Foundation Shibuya, Tokyo in 1981. The authors gratefully acknowledge the excellent technical assistance of Miss Kumiko Sugano for the tissue preparation and Mr. Ikuo Matsuyama for the preparing manuscript.

\section{References}

1) Cantley, L.C., Jr., Cantley, L.G., and Josephson, L. : A characterization of vanadate interactions with the $(\mathrm{Na}, \mathrm{K})$-ATPase; Mechanistic and regulatory implications. J. Biol. Chem., 253, 7361 $7368,1978$.

2) Grupp, G., Grupp, I., Johnson, C.M., and Schwartz, A. : Effects of vanadate and ouabain on contractile force of rat, guinea pig, rabbit and cat atria and ventricle. Fed. Proc., 38, 1042, 1979.

3) Nikolaeva, L.F., Cjerpachenko, N.M., Veselova, S.A., and Sokolova, R.I. : Mechanisms of drug action on recovery processes of cardiac muscle in myocardial infarction. Circ. Res., 24, 202 214, 1974 .

4) Brogden, R.N., Heel, R.C., Speight, T.M., and Avery, G.S. : A review of its pharmacology and therapeutic use in hypertension. Drugs, 15, 251, 1978.

5) Asano, G., Ashraf, M., and Schwartz, A. : Localization of Na-K ATPase in guinea pig myocardium. J. Mol. Cell. Cardiol., 12, 257 266, 1980. 
6) Asano, G., and Ashraf, M. : Cytochemical studies on peroxisomes in rat and guinea pig myocardium. Virchows Arch. [Cell Pathol.], 34, 205 212, 1980.

7) Novikoff, A.B. : The endoplasmic reticulum; A cytochemist's, view (a review). Proc. Natl. Acad. Sci. U.S.A., 73, 2781 2787, 1976.

8) Borgers, M., Schaper, J., and Schaper, W. : Localization of specific phosphatase activities in canine coronary blood vessels and heart muscle. J. Histochem. Cytochem., 19, 526 539, 1971.

9) Abersa, P., Loud, A.V., and Vitali-Mazza, L. : Morphometry and autoradiography of early hypertrophic changes in the ventricular myocardium of adult rat ; An electron microscopic study. Lab. Invest., 35, 475 483, 1976.

10) Ashraf, M., Asano, G., Millard, R.W., Matlib, M.A., Greenfield, J., and Schwartz, A. : Ultrastructural determinants of myocardial cell degeneration in hypertrophied dog myocardium. Lab. Invest., 42, 99, 1980 .

11) Sordahl, L.A., Macollum, W.B., Wood, W.G., and Schwartz, A. : Mitochondria and sarcoplasmic reticulum function in cardiac hypertrophy and failure. Am. J. Physiol., 244, 497 592, 1973.

12) Imai, K., Teitzer, W., Millard, R.W., Ashraf, M., Kranias, E.G., Asano, G., Grassi de Gende, A., Nagao, T., Solaro, R.J., and Schwartz, A. : Ischemia induced changes in canine cardiac sarcoplasmic reticulum. Fed. Proc., 38, 976, 1979.

13) Fawcett, D.W., and McNutt, N.S. : The ultrastructure of the cat myocardium. I. Ventricular paillary muscle. J. Cell Biol., 42, 1 44, 1969.

14) Wendt-Callitelli, M.F., Ebrecht, G.M., and Jacob, R. : Morphological alterations and their functional interpretation in the hypertrophied myocardium of galdblatt hypertensive rats. J. Mol. Cell Cardiol., 11, 275 287, 1979.

15) Janieson, J.D., and Palade, G.E. : Specific granules in atrial muscle cells. J. Cell Biol., 151 172, 1964 .

16) Hibbs, R.G., and Ferrans, V.J. : An ultrastructural and histochemical study of rat atrial myocardium. Am. J. Anat., 124, 251 280, 1968.

17) Ferrans, V.J., Hibbs, R.G., Buja, L.M. : Nucleoside phosphatase activity in atrial and ventricular myocardium of the rat; A light and electron microseopic study. Am. J. Anat., 125, 47 86, 1972 .

18) Schwartz.. A. : Is the cell membrane Na-K-ATPase enzyme system the pharmacological receptor for degitalis ? Circ. Res., 39., 2 7, 1976.

19) Willerson, J.T., Scales, F., Mukherjee, A., Platt, M., Templeton, G.H., Fink, G.S., and Buja, L.M. : Abnormal myocardial fluid retention as an early manifestation of ischemic injury. Am. J. Pathol., 87, 159 188, 1977.

20) Ashraf, M., Asano, G., and Lepera, R. : Histochemical distribution of Na-K ATPase in guinea pig and rat myocardium. Proc. Annual Meeting Electron Microscopy Society of North America, San Antonio, Texas, 1979.

21) Hackbarth, I., Sohmitz, W., Scholz, H., Erdmann, E., Krawietz, W., and Phillip, W. : Positive inotropism of vanadate in cat papillary muscle. Nature, 275, 7, 1978.

22) Adams, R.J., Wallick, E.T., Asano, G., Disalvo, J., Fondacaro, J.D., and Jacobson, E.D. : Canine mesenteric artery $\mathrm{Na}^{+} \mathrm{K}^{+}$ATPase; Vasopressor receptor for digitalis? J. Cardiovasc. Pharmacol., $\mathbf{5}$, in press.

23) Herzog, V., and Fahimi, H.D. : Microbodies (peroxisomes) containing catalase in myocardium; Morphological and biochemical evidence. Science, 185, 271 273, 1974.

24) Masters, C.J., and Holmes, R. : The metabolic roles of peroxisomes in mammalian tissues. J. Biochem. (Tokyo), 8, 549 553, 1977.

25) Hoffstein, S., Gennaro, D.E., Weissmann, G., Hirsch, J., Streuli, F., and Fox, A.C. : Cytochemical localization of lysosomal enzyme activity in normal and ischemic dog myocardium. Am. J. Pathol., 79, 193 206, 1975.

26) Muller, E., Pearse A.G.E., and Moss, E.W. : Rat atrial alkaline phosphatase activity and its response to isoprenaline during postnatal development. J. Mol. Cell. Cardiol., 4, 275 278, 1972 .

27) Ahmed, S.H., Rakhawy, M.T., Abdalla, A., and Assaad, E.I. : The comparative anatomy of the blood supply of cardiac ventricles in the albino rat and guinea pig. J. Anat., 126, 51 57, 1978 .

28) Borgers, M., Schaper, J., and Schaper, W: Localization of specific phosphatase activities in canine coronary blood vessels and heart muscle. J. Histochem. Cytochem., 19, 526 539, 1971.

\section{Legends}

Fig. 2 Ventricular muscle fiber shows junctional sarcoplasmic reticulum (ISR) closely applied to well developed T-tubules (T). guinea pig, $\times 36,000$, uranyl acetate $\&$ lead citrate

Fig. 3 Atrial muscle fiber shows prominent Golgi complex (G) assoicated with specific granules (SG). 
gunea pig, $\times 36,000$, uranyl acetate \& lead citrate

Fig. 4 Ventricular muscle fiber shows the sarcoplasmic reticulum (SR) which consists of simple net work or anastomosing tubules, continuous $Z$ lines. rat, $\times 36,000$, uranyl acetate \& lead citrate

Fig. 5 Atrial muscle fiber shows numerous sarcoplasmic reticulum (SR) in closely proximity to the plasma membrane (PM). guinea pig, $\times 36,000$, uranyl acetate $\&$ lead.citrate

Fig. 6 Reaction product of Na-K ATPase is seen on the inner side of the plasma membrane (PM) and T-tubule ( $T$ ) in myocardium which is affected by the addition of ouabain. rat, $\times 36,000$, uranyl acetate

Fig. $7 \mathrm{DAB}$ reaction product is localized in peroxisome $(\mathrm{P})$ which is seen in proximity to mitochondria and sarcoplasmic reticulum in ventricular cell. rat; $\times 30,000$, uranyl acetate

Fig. $8 \mathrm{DAB}$ reaction product is localized in peroxisomes (P) which are seen in proximity to the plasma membrane of atrial cell. rat, $\times 30,000$, uranyl acetate

Fig. 9 Atrial muscle fiber shows the reaction product of acid phosphatase in the sacs of the sarcoplasmic reticulum as well as subsarcolemmal cisterns. guinea pig, $\times 37,500$, uranyl acetate

Fig. 10 Ventricular muscle fiber shows alkaline phosphatase activity on the plasma membrane (arrow) of endothelial cell of capillary and heart cell. rat, $\times 6,000$, uranyl acetate

Fig. 11 Glucose-6-phosphatase is localized in the sacoplasmic reticulum and Golgi complex of heart cell. rat, $\times 36,000$, uranyl acetate 


\section{Plate (1)}

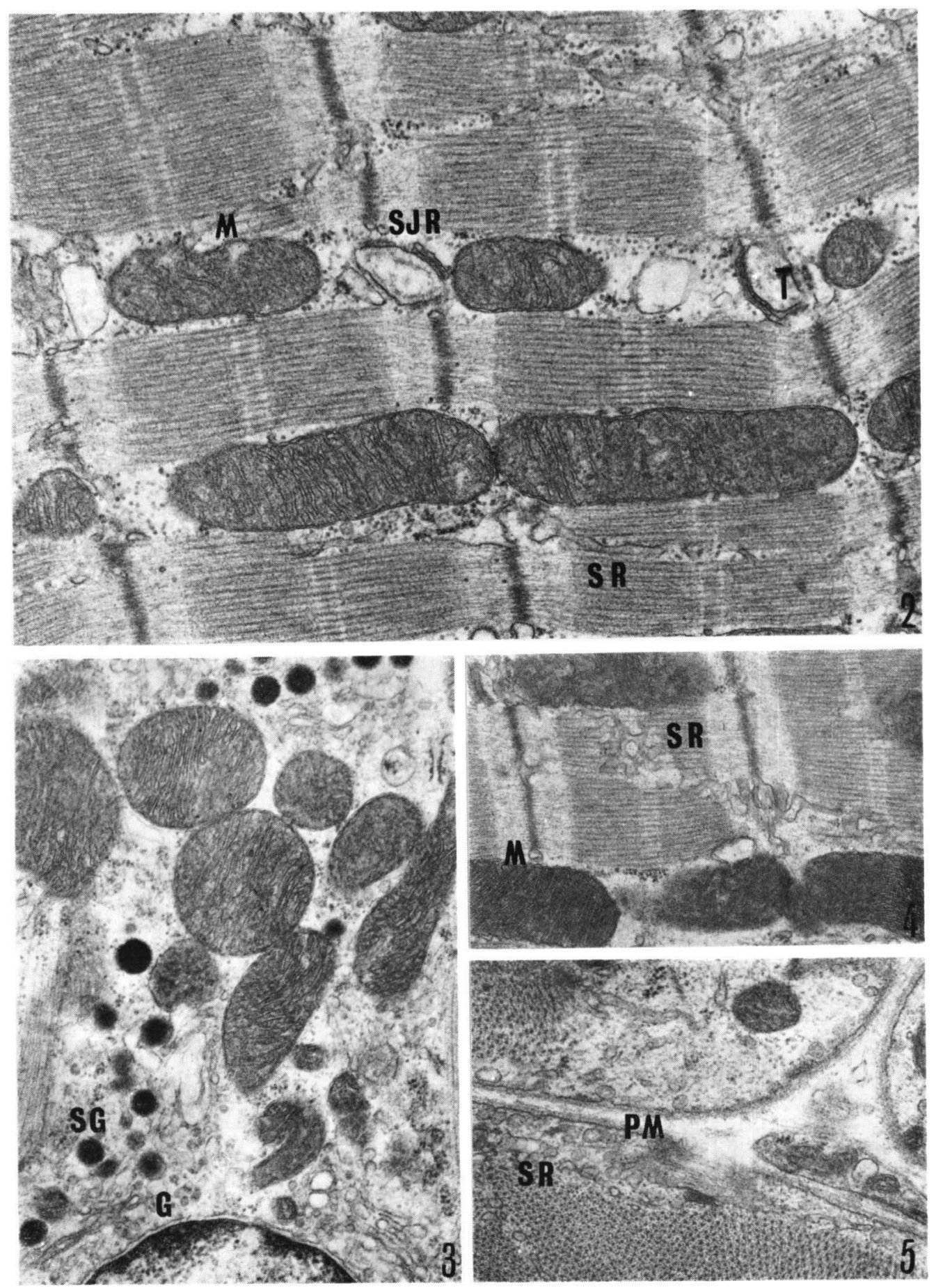


Plate (2)
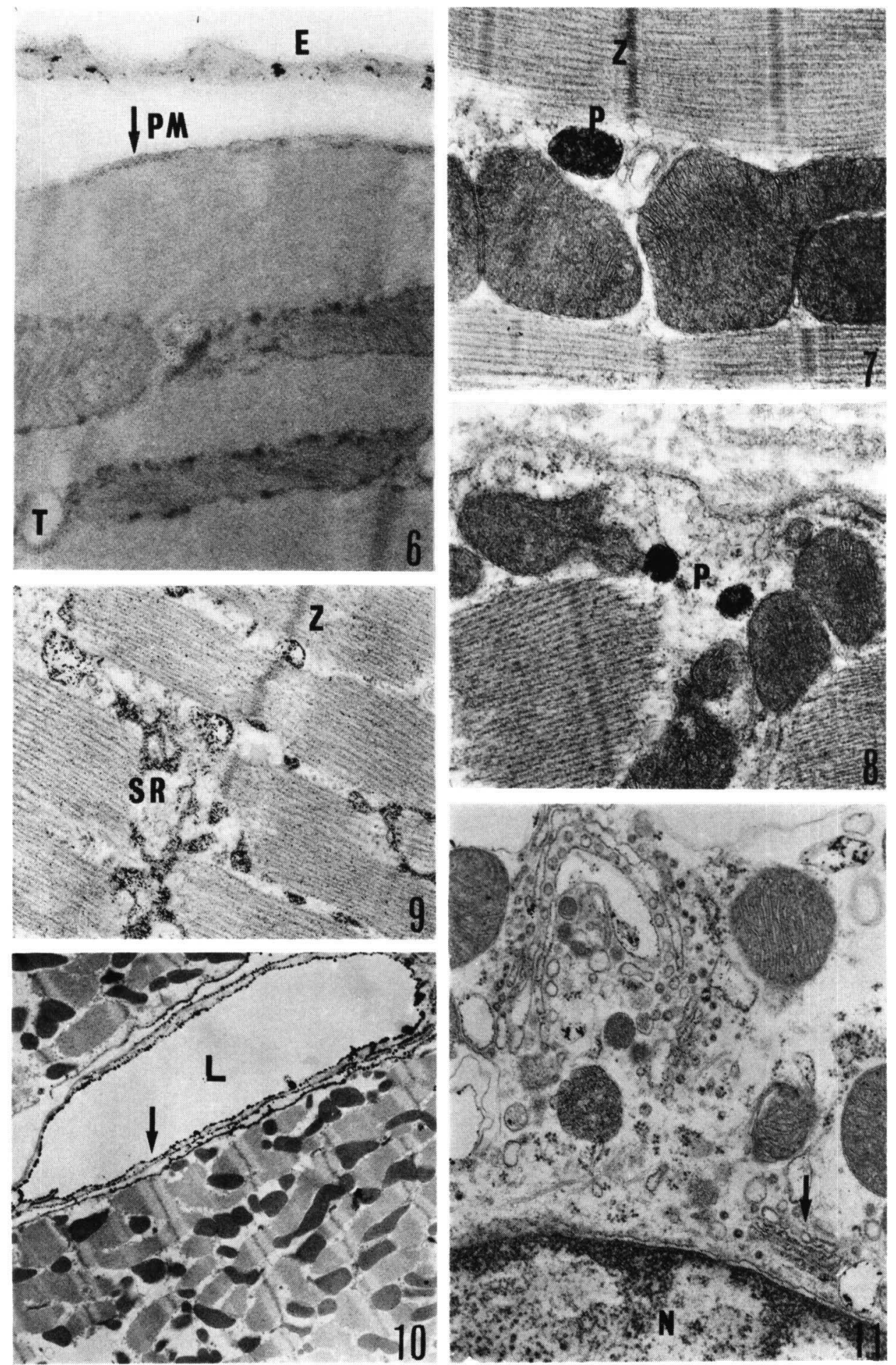